\title{
Causation of Metro Operation Accidents in China: Calculation of Network Node Importance Based on DEMATEL and ISM
}

\author{
Xin Wan $\mathbb{D}^{1,2}$, Yantong Zhang $\mathbb{D}^{1,2}$ Rubing Wang $\mathbb{D}^{1,2}$, Jingfeng Yuan $\mathbb{D}^{3},{ }^{3}$ Mengliu Hu $\mathbb{D}^{1},{ }^{1}$

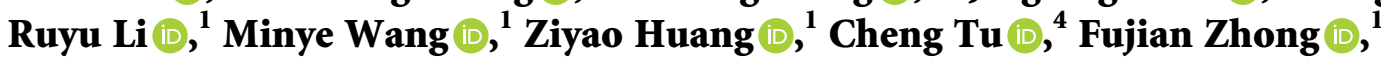 \\ and Wenjing Cui $\mathbb{1}^{1}$ \\ ${ }^{1}$ School of Business, Hohai University, Nanjing 211100, China \\ ${ }^{2}$ Institute of Engineering Management, Hohai University, Nanjing 211100, China \\ ${ }^{3}$ Department of Construction and Real Estate, Southeast University, Nanjing 210096, China \\ ${ }^{4}$ The Architectural Design \& Research Institute of Zhejiang University Co., Ltd., Hangzhou 310027, China
}

Correspondence should be addressed to Jingfeng Yuan; jingfeng-yuan@seu.edu.cn

Received 10 June 2021; Accepted 1 November 2021; Published 17 November 2021

Academic Editor: Siew Ann Cheong

Copyright (c) 2021 Xin Wan et al. This is an open access article distributed under the Creative Commons Attribution License, which permits unrestricted use, distribution, and reproduction in any medium, provided the original work is properly cited.

Continuous metro-operation accidents lead to serious economic loss and a negative social impact. The accident causation analysis is of great significance for accident prevention and metro operation safety promotion. Network node importance (NNI) evaluation has been widely used as a tool for ranking the nodes in complex networks; however, traditional indicators such as degree centrality (DC) are insufficient for examining accident networks. This study proposed an improved method by integrating decision making trail and evaluation laboratory (DEMATEL) and interpretive structural modeling (ISM) into traditional NNI evaluation, where the key nodes are determined by both the nature of the accident network topology and the contribution of the nodes to accident development. Drawing on this method, 32 accident causal factors were identified and prioritized on the ground of 248 accident cases. It was found that 14 important factors related to staff (e.g., "driver noncompliance"), environment (e.g., "extrinsic nature disturbance"), passenger (e.g., "passenger sudden illness"), and machine (e.g., "track failures") should be given priority in safety management due to their significant tendency of causing metro accidents. Theoretical and managerial implications were discussed to provide useful insights into the understanding of the causation of metro accidents and form a basis for metro managers to develop targeted safety countermeasures related to metro operation. The proposed hybrid method is proven effective in investigating accident networks involving sequential and casual relationships and revealing factors with high possibility to increase accidents.

\section{Introduction}

Urbanization and industrialization lead to the influx of people into cities resulting in severe traffic congestion and disorder. Urban metros provide an efficient and green solution for coping with the increasing traffic pressure. By the end of 2017, 642 metro lines with a total length of $13,903 \mathrm{~km}$ had been put into operation around the world [1]. Along with the great development of rail transit industry, the managers of cities and metro operation companies are under pressure of keeping safe and reliable operation of urban metros. According to the data provided by the China Association of Metro (https://www. camet.org.cn/), over the past five years (2016-2020), an average of 1493 delay events lasting more than five minutes occurred per year across the country. Preventing any kind of malfunctions and accidents in metro has become one of the most important agenda for increasing social stability and safety [2], especially in those cities with huge rail transit ridership. However, considering the safety of rail transit, much attention has been paid to exploring the solution of underground construction safety and accident prevention, while there is dearth of research focusing on the accident and safety issue of the metro at the operation stage. As such, this study aims to examine how diverse factors interacted to cause metrooperation accidents and prioritize these factors to target the key points for safety management of the metro operation. 
Since a safe operation of the metro depends heavily on the orderly cooperation of multisystems and elements, metro-operation accidents tend to be increased by multiple interacted hazards occurred following certain sequences or in the form of a network. In recent years, the network node importance (NNI) evaluation has been viewed as an effective tool for prioritizing the nodes or factors of a networked system [3], which has been successfully used to investigate, e.g., traffic networks $[4,5]$, power grids [6], and social networks [7, 8]. However, the traditional NNI evaluation reliant on indicators of network topology (e.g., degree centrality and betweenness centrality) is capable of examining the physical or social networks for whom connectivity and accessibility are predominate attributes of the nodes, but are insufficient for explaining networks containing causal relations such as accident networks. Combining decision making trail and evaluation laboratory (DEMATEL) with interpretive structural modeling (ISM), this study proposed an improved method to better assess the node importance of accident networks by allowing for the inclusion of how a factor contributes to the development of the accident. The improved method, as a result, provides a suitable tool for analyzing the networks involving cause and effect relations.

Three-fold contributions are presented in this study. First, from the theoretical viewpoint, this study proposed a more suitable method for ranking the node importance of accident networks by integrating DEMATEL and ISM into traditional NNI evaluation. Second, drawing on the real accident cases, the accident network of metro operation was established to prioritize the factors with the potential to cause operation accidents. Finally, from the managerial viewpoint, the findings laid down a foundation for metro mangers to formulate effective prevention strategies in order to reduce metro-operation accidents and boost a safe and reliable metro operation.

\section{Literature Review}

2.1. Chains-of-Events Modeling. By conceptualizing the characteristics of accidents, accident analysis explains why accidents happen and provides a tool for risk assessment during system development as well as post hoc accident causation analysis, up on which proper prevention measures can be conducted to reduce the occurrence of accidents of similar nature [9]. As large complex systems constitute multielements with regard to humans, machines, and the environment, a diversity of traditional and modern methods with their own merits have been employed to perform accident modeling and have contributed to the understanding of accidents (for a general review see [10]). Among them, the classic chains-of-event models explaining the accidents as a result of a series of events occurred following a particular logical order work well for capturing clear cause-effect relations between discrete or consecutive events.

Domino theory, as one of the earliest sequential eventbased models, implies that an accident is the result of a single cause, which can be described by five factors in sequence: social environment, fault of the person, unsafe acts or conditions, accident, and injury [11]. However, in most cases, the occurrence of an accident cannot merely attribute to a single contributing factor. In multilinear events sequencing (MES) model proposed by Benner [12], accidents were delineated as multiple sequences of events and conditions following a timeline, which provided a universal framework for explaining various accidents in a complete, reproducible, and conceptually consistent manner. The MES model has been in regular use by the US National Transportation Safety Board to investigate traffic accidents [13].

In systems engineering areas, fault tree analysis (FTA) and event tree analysis (ETA) abiding by deductive logic provide a standard hazard analysis method for identifying accident sequence and estimating its chance of occurrence [14]. However, the required occurrence probability of bottom events (e.g., failure rates) are usually unavailable due to the insufficiency and incompleteness of precise industry data sources [15]. Therefore, both FTA and ETA are most appropriate for systems or equipment made up by standard components with complete fault data, such as electrotechnical systems [16] and mechanical systems [17]. Another branch of systems engineering methods, including ISM, DEMATEL, and analytic hierarchy process (AHP), was proposed with matrix theory, providing an effective way of layering and structuring the elements of a system. As it is easy to measure the relations of any pair-wise elements in a system in virtue of accessible experts' opinion, these methods have been widely used to layer and prioritize the hazards of the systems in high-risk industries, such as coal mine [18], gas pipelines [19], and chemical plants [20].

Accidents in complex systems are manifestations of a latent accident causation network of related hazards [21]. By synthesizing a large number of accident sequences in the form of networks, complex network theory provides a framework for capturing the global properties and the intricate relations of the hazards with the potential to cause accidents. Recently, scholars have devoted to determining the factors being most worthy of safety control and resource allocation by examining the topological structure and characteristics of a certain type of accident network [4, 22, 23]. Taking rail traffic accident analysis as an example, Chen et al. [24] constructed an urban transit disaster network to identify the important factors contributing to avoiding accident. Similarly, by analyzing the topological characteristics of a metro construction accident network, Zhou et al. [23] suggested that controlling undesirable events such as explosion can decrease the accident propagation efficiency.

\subsection{The Evaluation of Network Node Importance.} Complex networks abstracted from a complex system usually consist of a large number of intricate connected nodes; wherein, however, only a few play a dominant role in deciding network mechanisms such as cascading, diffusing, and synchronizing $[25,26]$. Therefore, the evaluation of network node importance is of great significance in controlling propagation processes on the network, which has aroused great research interest of academia in the recent years.

There are many traditional methods focusing on the centrality of the node with different considerations to 
evaluate the node importance of complex networks, such as degree centrality (DC), betweenness centrality (BC), closeness centrality (CC), eigenvector centrality (EC), and PageRank [27]. DC referring to the degree of each node is the simplest method to rank the importance of nodes, but is criticized for neglecting useful information due to only focusing on the number of neighbors [28]. Being path-based centralities, $\mathrm{BC}$ and $\mathrm{CC}$ measure the node importance on the basis of the shortest path between nodes. BC considers the number of the shortest paths passing through a node, while $\mathrm{CC}$ evaluates the node importance by the average length of the shortest path from each node to the other nodes [29]. Despite being widely applied to NNI evaluation, high computational complexity of BC and CC hinders them from being generalized to large-scale networks [30]. Methods based on iterative refinement centrality, such as EC and PageRank, were proposed to measure the importance of node by using interactive algorithms [31,32]. These indicators determine the importance of each node by considering not only the number of its neighbors but also by the importance of each neighbor, known as the mutual enhancement effect [33]. Although these traditional methods have been demonstrated to be effective in identifying important nodes in, e.g., transportation networks [34], power communication networks [35], and social networks [36], they are mostly confined to the examination of network topology.

Scholars have also attempted to put forward new indicators or integrate other methods into traditional NNI evaluation, rather than merely focusing on the nature of the network topology from a certain perspective by using traditional indicators. Inspired by the multiple-attribute decision making (MADM), some scholars aggregated different network attributes of node (e.g., DC, BC, and K-shell decomposition) leveraging methods such as the evidence theory and the technique for order preference by similarity to an ideal object (TOPSIS) to develop a multiattribute ranking method $[37,38]$. The experimental results indicated that the comprehensive indicators outperformed the use of a single traditional evaluation indicator. In the research of Meng et al. [39], TOPSIS together with coefficient of variation was applied for the identification of important nodes, where the best improvement was that different attributes of the nodes were weighted before aggregating. To reasonably weight the network nodes, Hu et al. [40] developed a way of combining ISM with traditional NNI evaluation and validated the effectiveness of the combined method by the simulations on the Advance Research Project Agency (ARPA) network. Besides, a structural hole, which denotes a gap between two unconnected nodes and originates from the attempt to explore the competitive relationships in a network, has been demonstrated to be effective in identifying the important bridge nodes (i.e., the key individuals) in social networks [41, 42].

2.3. Research Gap. It is of great theoretical and practical significance to examine causal mechanisms and identify important causes of accidents in order to enhance the safety of large complex systems. The sequential accident model has been expanded from simply tracing a single contributing factor to comprehensively considering multiple factors and multiple sequences of the hazards derived from different aspects. With the capacity of prioritizing multitudinous nodes with complex interactions, network node importance evaluation is one of the most promising domains in the analysis of complex systems or issues. However, still some gaps should be noticed.

First, ISM, DEMATEL, and AHP are effective methods for exploring the structures and layers of a complex system involving a diversity of elements. The key point for the application of these methods lies in how to reasonably determine the relations between different factors. However, the relations are always measured artificially, e.g., in accordance with expert opinions, which varies considerably from person to person, and compared to using historical case data are criticized for subjectivity [43, 44]. Second, in order to increase the effectiveness and accuracy of node importance ranking in complex networks, great endeavor has been made to improve the traditional NNI evaluation methods by a variety of prior studies. However, these methodology-driven improvements have largely ignored the discrepancy of the nodes derived from the actual world from which the network was abstracted. That is, for example, an accident network is different from a physical network (e.g., a transportation network or a power grid) in terms of logical relationships since the former embodies a kind of causal relationships and the latter reflects the routes of traffic or energy flow in the network. Taking this reality into consideration is beneficial for a well combination of theory and practice, thus promoting the practical significance of the research. Third, as for the studies focusing on accident causation analysis, there is a dearth of methods being designed to adapt to the evaluation of node importance of accident networks. On account of the aforementioned characteristics of accident networks, it is more reasonable to determine the importance of a factor in light of its contribution to the sequence or cause-effect relations of the accident, rather than merely from the perspective of topology or network attributes, which is more applicable to ranking the nodes in physical networks.

To bridge these research gaps, this study proposed an improved method for assessing the node importance of accident networks by introducing DEMATEL and ISM. In the improved method, the relations of different accident causal factors can be determined by the real accident cases rather than expert opinion only, and all the factors can be layered and weighted according to their contributions to the occurrence and development of the accident. The improved evaluation method provides a more accurate and suitable tool for prioritizing the nodes in accident networks and was applied to fully examine the important causes of metrooperation accidents in this study.

\section{Research Methodology}

3.1. Framework of Methodology. In spite of being an effective tool for establishing the hierarchical structure of the factors, ISM reliant on the binary algorithm, in which 1 and 0 is, 
respectively, representative of having or having no relationships, is unable to show partial relationships between factors. In this regard, DEMATEL with the ability to describe the different sizes of influences between factors was combined with ISM to provide a more powerful method for examining the node importance of accident networks and identifying the key causes of metro-operation accidents in this study (Figure 1).

First, usable cases, literature review, and field interview were combined to form the basis for the establishment of an accident causal factor list and accident chains. The DEMATEL can be initialized by using the data extracted from the accident chains. Subsequently, the comprehensive influence matrix obtained from DEMATEL was used to initialize the ISM, and then a multilevel hierarchical structure model was produced by conducting alternate extraction on the reachability matrix. Finally, referring to the work of $\mathrm{Hu}$ et al. [40], the node importance index (NII) of each factor was calculated according to the weighted in- and out-degrees of the nodes, where the weights were determined by the position of the nodes in the multilevel hierarchical structure.

3.2. DEMATEL and ISM Method. DEMATEL and ISM were integrated in accordance with the following steps to layer the causal factors of metro-operation accidents.

Step 1: Denote various accident causal factors such as $X_{1}, X_{2}, \ldots, X_{n}$, making up the factor set $X$, where $n$ equals the number of factors.

Step 2: Denote the number of times that factor $X_{i}$ occurred as $a_{i}$.

Step 3: Calculate the direct influence matrix.

Assume that $\mathbf{L}=\left(l_{i j}\right)_{n \times n}(i, j=1,2, \ldots, n)$ is the $n \times n$ factor association matrix, where $l_{i j}$ represents the number of times that factor $X_{i}$ points to factor $X_{j}$, and $l_{i j}=0$ when $i=j(i, j=1,2, \ldots, n)$. The direct influence matrix $\mathbf{R}$ is calculated on the basis of the factor association matrix $\mathbf{L}$ by using the equation as follows:

$$
\mathbf{R}=\left(r_{i j}\right)_{n \times n}=\left(\frac{l_{i j}}{a_{j}}\right)_{n \times n},
$$

where $r_{i j}$ represents the direct influence of factor $X_{i}$ on factor $X_{j}$, and $a_{j}$ is the number of times that factor $X_{j}$ occurred.

Step 4: Compute the standardized direct influence matrix as follows:

$$
\mathbf{B}=\left(b_{i j}\right)_{n \times n}=\frac{1}{\max _{1 \leq i \leq n}\left(\sum_{j=1}^{n} r_{i j}\right)} \mathbf{R},
$$

where $b_{i j}$ represents the standardized direct influence of factor $X_{i}$ on factor $X_{j}$.

Step 5: Calculate the comprehensive influence matrix. The comprehensive influence matrix $\mathbf{T}$ reflecting both direct and indirect relationships between factors is established as follows:

$$
\mathbf{T}=\left(t_{i j}\right)_{n \times n}=\mathbf{B}+\mathbf{B}^{2}+\cdots+\mathbf{B}^{n}=\mathbf{B} \frac{\mathbf{E}-\mathbf{B}^{n-1}}{\mathbf{E}-\mathbf{B}},
$$

where $t_{i j}$ represents the comprehensive influence of factor $X_{i}$ on factor $X_{j}$, and $\mathbf{E}$ is the unit matrix.

Step 6: Calculate the overall influence matrix.

The overall influence matrix $\mathbf{H}$ adding the influence of the factor on itself on the basis of the comprehensive influence relationship among factors, which can be expressed as follows:

$$
\mathbf{H}=\left(h_{i j}\right)_{n \times n}=\mathbf{T}+\mathbf{E},
$$

where $h_{i j}$ represents the overall influence of factor $X_{i}$ on factor $X_{j}$.

Step 7: Determine the threshold value $\lambda$ and establish the reachability matrix.

To highlight the major effects among accident causal factors without oversimplification, a proper threshold value $\lambda$ should be set up to filter out the overall influence, which is smaller than $\lambda$. Based on equation (5), reachability matrix $\mathbf{K}$ can be established as

$$
\mathbf{K}=k_{i j} \begin{cases}=1, & h_{i j} \geq \lambda, \\ =0, & h_{i j}<\lambda,\end{cases}
$$

where $k_{i j}=1$ represents the strong relation between two factors, and $k_{i j}=0$ represents no or weak relation.

Step 8: Establish the multilevel hierarchical structure model.

With the establishment of reachability matrix $\mathbf{K}$, the reachable set $D\left(X_{i}\right)$ and the antecedent set $A\left(X_{i}\right)$ can be obtained as follows:

$$
D\left(X_{i}\right)=\left\{X_{j} \mid X_{j} \in X, k_{i j}=1\right\},
$$

where the elements accordant to the columns with 1 in $i$-th row of the reachability matrix $\mathbf{K}$ make up the reachable set $D\left(X_{i}\right)$;

$$
A\left(X_{i}\right)=\left\{X_{j} \mid X_{j} \in X, k_{j i}=1\right\},
$$

where the elements accordant to the rows with 1 in the $i$-th column of the reachability matrix $\mathbf{K}$ make up the antecedent set $A\left(X_{i}\right)$;

$$
J\left(X_{i}\right)=D \cap A
$$

where the intersection set $J\left(X_{i}\right)$ is composed of the elements both contained in the reachable set and the antecedent set.

The alternate extraction principle was adopted to form the multilevel hierarchical structure. All factors that satisfy $D\left(X_{i}\right)=J\left(X_{i}\right)$ are grouped into the top layer, and the row and column to which the factors belong to will be removed from the reachability matrix K. $D\left(X_{i}\right), A\left(X_{i}\right)$, and $J\left(X_{i}\right)$ are accordingly updated. Then, the factors are classified into the bottom layer if they satisfy $A\left(X_{i}\right)=J\left(X_{i}\right)$, and the corresponding row and column are removed from the matrix $K$. 


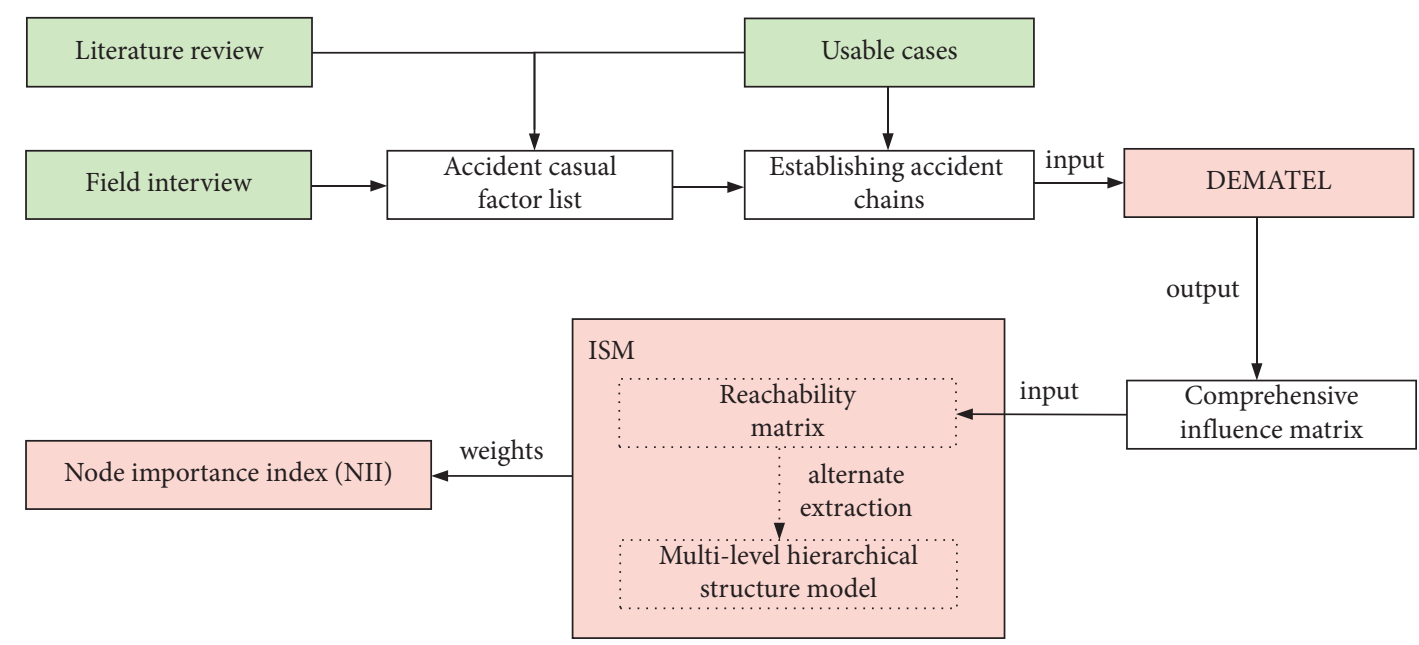

FIGURE 1: Framework of methodology.

By iterating the above processes until all factors are allocated, a multilevel hierarchical structure model can be obtained.

3.3. Network Node Importance Evaluation. The node importance index is calculated on the basis of the DEMATEL and ISM to identify the importance of factors influencing metro operation safety, and the detailed steps are given below.

Step 1: Define network hierarchy.

Assuming that the hierarchical structure model classifies the accident causal factors into $N$ layers, which are coded as $\operatorname{Lx}(x=1,2,3, \ldots, N)$. Since the factors located in the deeper level are prone to take an underlying part in the formation of an accident, in this study the importance order of the hierarchical model is defined as $L_{N}>L_{N-1}>\cdots>L_{1}$, and $L x$ is assigned as follows:

$$
L_{1}=N, \quad L_{2}=N-1, \ldots, L_{N}=1 .
$$

Step 2: Determine the weight of each layer in the hierarchical model.

$$
Q_{x}=\frac{1 / L_{x}}{\sum_{1}^{N}\left(1 / L_{x}\right)}
$$

where $Q_{x}$ is the weight of the layer.

Step 3: Calculate the NII of each accident causal factor based on the relations between factors showed in the reachability matrix.

$$
N I I_{i}=Q_{i}\left(I \sum_{k} Q_{k \longrightarrow i} D_{k \longrightarrow i}+O \sum_{j} Q_{i \longrightarrow j} D_{i \longrightarrow j}\right)
$$

where $N I I_{i}$ is the node importance index of the factor $X_{i}, Q_{i}$ is the weight of the layer in which the factor $X_{i}$ is located, $Q_{k \longrightarrow i}$ are the weights of the layers in which the factors $X_{k}$, which point to $X_{i}$, are located, $D_{k \longrightarrow i}$ are the number of $X_{k}$, which point to $X_{i}$, in each layer, $Q_{i \rightarrow j}$ are the weights of the layer in which the factors $X_{j}$, which are pointed by $X_{i}$, are located, and $D_{i \rightarrow j}$ are the number of $X_{j}$, which are pointed by $X_{i}$, in each layer, and $I O$ are, respectively, the weights of $X_{k}$, which point to $X_{i}$ and $X_{j}$, which are pointed by $X_{i}$.

\section{Application of the Proposed Method}

4.1. Data Collection. Given the absence of officially published metro-operation accident data, the way of collecting cases in this study included: (1) extant literature including academic journals and relevant books; (2) reports and news published on media platforms held by authorities, professional organizations, and formal social groups, such as official metro websites of various cities, metro-related fora, and news media; and (3) metro operation records, including 1089 cases from December 2018 to December 2019, obtained from metro operation companies in China.

As a result, a total of 379 incidents covering the period of 2005 to 2019 were preliminarily obtained. Since not all of these incidents were sufficient and suitable for causation analysis, cases with the following attributes remained and were employed in the subsequent analysis: (1) integritybeing clear regarding the key information and process of the accident; (2) substantiality-normally having substantive impacts on, e.g., train operation and physical safety; and (3) representativeness-being representative of a certain type of metro accident rather than an exception. Accordingly, 248 usable accident cases conforming to the above criteria were retained and used to evaluate the importance of the causal factors of metro-operation accidents.

4.2. Accident Causal Factors and Chain Extraction. An elaborative procedure was developed to obtain multifaceted information on the causes of a metro-operation accident. First, based on the selected accident cases and literature review, 27 factors were summarized in terms of passenger, staff, machine, environment, and consequence to form the initial accident causal factor list. Second, the interviews with 3 scholars majoring in transportation and safety management, and 4 managers of metro operation companies serving 
as the operation director, dispatch supervisor, and safety supervisor were conducted to assess the correctness and appropriateness of the identification and definition of the factors. Following the expert's comments, the initial accident causal factor list was modified and improved by adding new factors or merging and splitting the original factors. For example, the extrinsic disturbance was subdivided into "extrinsic nature disturbance (E1)" and "extrinsic non-nature disturbance (E2)". The factors such as "passenger uncivilized behaviors (P3)", "improper use of facilities (P6)", and "fire or flood (E3)" were added into the factor list for their salient influence on accident occurrence according to the experience of the experts. Besides, the description and expression of each identified factor was further refined according to the suggestions of experts. Consequently, a final list containing 32 accident causal factors was finally obtained (Table 1), with 10 passenger-related factors (P1-P10), 5 staffrelated factors (S1-S5), 6 machine-related factors (M1-M6), 6 environment-related factors (E1-E6), and 5 consequencerelated factors (C1-C5).

Carrying the information on causation and process of an accident, various accident chains were abstracted by the historical accidents selected in this study, upon which relations between different causal factors would be determined. Nodes sequentially connected by arrow lines form a typical chain of the accident, where the nodes are representative of the accident casual factors, and directional lines denote the interrelationships between the factors. Since an accident may develop in a single or a multilinear form, the number of chains is usually greater than the number of cases. In this study, taking 32 identified accident causal factors such as the nodes, 288 accident chains were established corresponding to the accident sequences displayed by the 248 metro operation cases. This process is illustrated in Table 2 by taking cases 16, 113, 156, and 208 as examples.

4.3. DEMATEL and ISM Analysis. In order to layer the identified factors of metro accidents, the DEMATEL and ISM analyses were performed following step 1 to step 8 in 3.2.

First, the direct influence matrix $\mathbf{R}$ can be calculated according to equation (1), where, it should be noted that the number of times that factor $X_{i}$ occurred $\left(a_{i}\right)$ are presented in Table 1, and the factor association matrix $\mathbf{L}$ was formed by counting the number of times that factor $X_{i}$ points to factor $X_{j}$ based on 288 accident chains. By performing equation (2), the direct influence matrix $R$ was normalized to obtain the standardized direct influence matrix $\mathbf{B}$. Then, the comprehensive influence matrix $\mathbf{T}$ (see Table 3 ) was calculated by using equation (3).

According to equation (4), the unit matrix $\mathbf{E}$ was added to the comprehensive influence matrix $\mathbf{T}$ to establish the overall influence matrix $\mathbf{H}$. According to expert suggestions and repeated tests, the threshold value $\lambda$ was set as 0.05 , upon which the reachability matrix $\mathbf{K}$ (see Table 4 ) can be obtained according to equation (5). Then, by performing equations (6), (7), and equation (8), the reachable set $D\left(X_{i}\right)$, antecedent set $A\left(X_{i}\right)$, and intersection set $J\left(X_{i}\right)$ were obtained.
Finally, following the alternate extraction principal, a 7-level hierarchical model was produced (Figure 2).

As shown in Figure 2, the factors located in the deep level $\left(L_{7}\right)$ of the structure model were regarded as the underlying causes of the accidents, which instead of being influenced by other factors, showed strong influence on other factors. The surface level $\left(L_{1}\right)$ collected the direct causes or the consequences of the accident, which would be triggered by the deeper factors. The causes included in $L_{6}$ to $L_{2}$ played a transitive role in the formation and development of the accident. It is noteworthy that P4 and S4 had no incidence edge due to their weak links with other factors.

4.4. Network Node Importance Analysis. The NII was calculated to determine the priority of the factors contributing to metro-operation accidents. As is explained earlier, the importance order of the hierarchical model was defined as $L_{7}>L_{6}>\cdots>L_{1}$. Accordingly, the weights of the layer $\left(Q_{x}\right)$ can be calculated by using equations (9) and (10): $Q_{1}=0.055 ; Q_{2}=0.064 ; Q_{3}=0.077 ; Q_{4}=0.096 ; Q_{5}=0.129 ;$ $Q_{6}=0.193 ; Q_{7}=0.386$.

Then, the number of $X_{k}$, which point to $X_{i}$ in each layer $\left(D_{k \rightarrow i}\right)$ and the number of $X_{j}$, which are pointed by $X_{i}$ in each layer $\left(D_{i \longrightarrow j}\right)$ were extracted from reachability matrix $\mathbf{K}$. As the importance of a node in a network can be better reflected by its influence on other factors than the influence from other factors, this study assigns a higher weight to $X_{j}$, which are pointed by $X_{i}(O)$ than $X_{k}$ who point to $X_{i}(I)$. As suggested by experts, the $O$ and $I$ were assigned 0.75 and 0.25 , respectively. Finally, the NII of 32 factors was determined by equation (11).

As shown in Table 5, taking the mean NII value of 32 accident causal factors (0.0274) as the boundary, 13 factors with the NII value higher than 0.0274 , and M3 whose NII $(0.0262)$ was very close to the mean value were classified as the high-rank regarding their significant role in causing a metro-operation accident. Naturally, the remaining 18 factors were determined as the low-rank, which were supposed to be relatively less important for promoting the accident.

According to the mean NII values of different factor categories, the staff-related factors ranked first $(\mathrm{NII}=0.0403)$, largely due to the significant high NII value of "driver noncompliance (S5)" (0.1436), which was almost twice as high as the second factor E1 (0.0837). Another factor in staff category closely connected with the occurrence of metro accidents and located in the high-rank was "traffic dispatching errors (S3)". Owing to four of the six factors involved in the high-rank, the environment-related factors $(\mathrm{NII}=0.0370)$ took the second place of all categories. The results showed that metro operation was vulnerable to both the extrinsic nature (E1) and non-nature (E2) disturbance. In addition, the defects left over from design or construction stage (E4) and the intrusion of person or their items into metro gauge (E6) can significantly increase the number of accidents. With half of the factors located in high-rank, the passenger-related factors ranked third $(\mathrm{NII}=0.0282)$. On the one hand, passenger sudden illness (P2) and suicide (P1) 
Table 1: Accident causal factor list.

\begin{tabular}{|c|c|c|}
\hline Accident causal factors & Description & $\begin{array}{l}\text { The } \\
\text { occurrence } \\
\text { number }\end{array}$ \\
\hline \multicolumn{3}{|l|}{ Passenger-related factors } \\
\hline $\mathrm{P} 1^{\mathrm{ab}}$. Passenger suicide & Passengers commit suicide by jumping or lying on the tracks [45] & 23 \\
\hline $\mathrm{P} 2^{\mathrm{abc}}$. Passenger sudden illness & Passengers suddenly feel ill when riding a metro, e.g., faint [46] & 10 \\
\hline $\begin{array}{l}\mathrm{P}^{\mathrm{abc}} \text {. Passenger uncivilized } \\
\text { behaviors }\end{array}$ & $\begin{array}{c}\text { Passengers act against social moralities or ethics such as grabbing seats, littering, } \\
\text { spreading wrong information, etc. [47] }\end{array}$ & 12 \\
\hline $\mathrm{P} 4^{\mathrm{abc}}$. Personal conflicts & Behaviors of fights and quarrels between people in the metro [47] & 12 \\
\hline $\begin{array}{l}\mathrm{P} 5^{\mathrm{abc}} \text {. Passenger's belonging } \\
\text { aberration }\end{array}$ & $\begin{array}{l}\text { Passengers carry potentially dangerous items or their items are in the abnormal state, } \\
\text { such as items caught by doors, dropping onto tracks, or smoking and burning [48] }\end{array}$ & 12 \\
\hline $\mathrm{P}^{\mathrm{abc}}$. Improper use of facilities & $\begin{array}{l}\text { Passengers use switches, buttons, or equipment on the train or station in a wrong way } \\
\text { or in an inappropriate situation [47] }\end{array}$ & 11 \\
\hline $\begin{array}{l}\mathrm{P}^{\mathrm{abc}} \text {. Passenger's dangerous } \\
\text { behaviors }\end{array}$ & $\begin{array}{l}\text { Passengers' high-risk behaviors during riding a metro, including forcing the platform } \\
\text { screen door or the train door open, crossing the rail to reach another platform, jumping } \\
\text { over the gate machine, etc. [47] }\end{array}$ & 29 \\
\hline $\mathrm{P}^{\mathrm{ac}}$. Passenger panic & A mass of passengers under chaos, panic, or fear & 24 \\
\hline $\mathrm{P} 9^{\mathrm{abc}}$. Passenger got stuck & $\begin{array}{c}\text { Passengers' bodies are caught by the devices or get stuck in the gap between the devices } \\
\text { or facilities, such as screen doors, train doors, platforms, and trains [49] }\end{array}$ & 19 \\
\hline $\begin{array}{l}\mathrm{P} 10^{\mathrm{ab}} \text {. Passenger falling onto the } \\
\text { tracks }\end{array}$ & Passengers fall onto the main track areas of a metro [48] & 49 \\
\hline \multicolumn{3}{|l|}{ Staff-related factors } \\
\hline$S 1^{\mathrm{abc}}$. Information delivery errors & $\begin{array}{c}\text { Errors in the content, objects, and timing of messages during information } \\
\text { communication and transmission process between metro staff caused due to human } \\
\text { mistakes [50] }\end{array}$ & 6 \\
\hline $\mathrm{S}^{\mathrm{abc}}$. Poor maintenance & $\begin{array}{l}\text { Inadequate repair and maintenance of facilities, equipment, pipelines, etc. because of } \\
\text { an improper maintaining schedule or workers' errors [51] }\end{array}$ & 14 \\
\hline $\mathrm{S}^{\mathrm{abc}}$. Traffic dispatching errors & $\begin{array}{l}\text { Errors in the process of vehicle dispatch, for example, publishing a wrong train } \\
\text { scheduling command or defects in the scheduling plan itself [52] }\end{array}$ & 11 \\
\hline $\mathrm{S} 4^{\mathrm{abc}}$. Inadequate station inspection & $\begin{array}{l}\text { Metro stations lack inspection and regulation from metro staff and other institutions } \\
\text { such as the public security department [46] }\end{array}$ & 8 \\
\hline $\mathrm{S}^{\mathrm{abc}}$. Driver noncompliance & $\begin{array}{l}\text { Train drivers disobey operation rules, including any noncompliance behaviors during } \\
\text { daily driving or emergency disposal [53] }\end{array}$ & 29 \\
\hline \multicolumn{3}{|l|}{ Machine-related factors } \\
\hline$M 1^{\text {abc }}$. Power supply failures & Local or wide-area break down of traction power supply or lighting power supply [54] & 40 \\
\hline $\begin{array}{l}\mathrm{M} 2^{\mathrm{abc}} \text {. Signal and communication } \\
\text { system failures }\end{array}$ & $\begin{array}{l}\text { Faults in signal and communication systems in the process of information and signal } \\
\text { reception, dispatch, and disposal, such as repeated transmission and communication } \\
\text { interruption [4] }\end{array}$ & 17 \\
\hline $\mathrm{M}^{\mathrm{abc}}$. Vehicle failures & Malfunction of the components and equipment on the train [54] & 62 \\
\hline $\mathrm{M} 4^{\mathrm{abc}}$. Station facility failures & $\begin{array}{l}\text { Service facilities of a metro station including elevators, escalators, gate machines, } \\
\text { mobile payment system, etc., but not platform screen doors, are out of function }[55]\end{array}$ & 23 \\
\hline M5 ${ }^{\mathrm{abc}}$. Platform screen door failures & Platform screen doors are out of function [55] & 10 \\
\hline$M 6^{\mathrm{abc}}$. Track failures & $\begin{array}{c}\text { Damage or malfunction of rails, rail switches, and supporting structures that may affect } \\
\text { train operation [21] }\end{array}$ & 17 \\
\hline \multicolumn{3}{|l|}{ Environment-related factors } \\
\hline E1 ${ }^{\text {ac }}$. Extrinsic nature disturbance & $\begin{array}{l}\text { Disturbance from earthquake, Hurricane, rainstorm, thunder and lightning, ice and } \\
\text { snow, haze, etc. }\end{array}$ & 25 \\
\hline $\begin{array}{l}\mathrm{E} 2^{\mathrm{ac}} \text {. Extrinsic non-nature } \\
\text { disturbance }\end{array}$ & Disturbance from deliberate sabotage or foreign objects & 23 \\
\hline $\mathrm{E} 3^{\mathrm{ac}}$. Fire or flood & Sparks, fires, floods, and other issues related to fire treatment occur in a metro & 14 \\
\hline $\mathrm{E} 4^{\mathrm{ac}}$. Design and construction faults & $\begin{array}{l}\text { Deficiencies left over from design or construction stage, such as outdated or defective } \\
\text { design, unqualified materials or equipment, and substandard construction }\end{array}$ & 11 \\
\hline $\mathrm{E} 5^{\mathrm{abc}}$. Congestion & $\begin{array}{c}\text { The riding environment is crowded and chaotic because of the large passenger flow or } \\
\text { people gathering [48] }\end{array}$ & 23 \\
\hline $\mathrm{E} 6^{\mathrm{abc}}$. Intrusion of the metro gauge & $\begin{array}{c}\text { Invasions of passenger or object into the gauge or protection zone of a metro without } \\
\text { permission [47] }\end{array}$ & 89 \\
\hline \multicolumn{3}{|l|}{ Consequence-related factors } \\
\hline $\mathrm{C} 1^{\mathrm{ac}}$. Derail & Trains get off tracks during operation & 6 \\
\hline $\mathrm{C} 2^{\mathrm{ac}}$. Collision & Trains collide with persons, objects, or other trains & 44 \\
\hline $\begin{array}{l}\mathrm{C} 3^{\mathrm{ac}} \text {. Degradation of operation } \\
\text { service }\end{array}$ & $\begin{array}{l}\text { Degradation or interruption of transport services such as train delay, speed reduction } \\
\text { or limit, skip-stop running, clearing off passengers, etc. }\end{array}$ & 221 \\
\hline
\end{tabular}


TABLE 1: Continued.

\begin{tabular}{lcc}
\hline Accident causal factors & Description & $\begin{array}{c}\text { The } \\
\text { occurrence } \\
\text { number }\end{array}$ \\
\hline $\mathrm{C} 4^{\text {ac }}$. Passenger casualties & Injury or death of passengers in the course of riding metros & 64 \\
$\mathrm{C} 5^{\mathrm{ac}}$. Occupational injuries & Injury or death of metro staff arising out of or in the course of work & 9 \\
\hline
\end{tabular}

Note: ${ }^{a}$ factors identified from cases, ${ }^{b}$ factors identified from literature review, ${ }^{c}$ factors identified or modified according to expert's interview.

TABLE 2: Typical cases for establishing the accident chains.

\begin{tabular}{|c|c|c|c|}
\hline $\begin{array}{l}\text { Case } \\
\text { no. }\end{array}$ & Description of accident process & $\begin{array}{l}\text { Accident causal } \\
\text { factors } \\
\text { extraction }\end{array}$ & Accident chain \\
\hline 16 & $\begin{array}{l}\text { On July 5, 2010, at Zhongshan park station of shanghai metro, a passenger tried to board } \\
\text { the train after the door-close alarm sounded (P7). As the door closed, one of the } \\
\text { passenger's hand was caught by the train door (P9) and intruded into the gauge of tunnel } \\
\text { (E6). Because of failure to observe, the driver did not see the danger and started the train } \\
\text { normally (S5), which led the passenger to crash into the safety barrier and die (C4). }\end{array}$ & $\begin{array}{c}\text { P7, P9, E6, S5, } \\
\text { C4 }\end{array}$ & $\begin{array}{l}\mathrm{P} 7 \rightarrow \mathrm{P} 9 \rightarrow \mathrm{E} 6 \\
\rightarrow \mathrm{S} 5 \rightarrow \mathrm{C} 4\end{array}$ \\
\hline 113 & $\begin{array}{l}\text { On November } 19,2012 \text {, at Xiamen metro line } 8 \text {, a short circuit occurred because the } \\
\text { pantograph touched the roof of a carriage (M1). A large plume of smoke, together with } \\
\text { sparks, were produced, and the smoke diffused into the carriages (E3). The driver stopped } \\
\text { the train in the tunnel, but, due to panic, some passengers opened the train doors and } \\
\text { thousands of uncontrollable people flooded into the tunnel to escape (P8). This finally } \\
\text { resulted in } 4 \text { passengers being injured in the chaos (C4) and a } 64 \text { minutes delay (C3). }\end{array}$ & $\begin{array}{c}\text { M1, E3, P8, C3, } \\
\text { C4 }\end{array}$ & $\mathrm{M} 1 \rightarrow \mathrm{E} 3$ \\
\hline 156 & $\begin{array}{l}\text { On March 30,2013, at Guangzhou metro line 3, the persistent thunderstorm and strong } \\
\text { wind (E1) caused a short circuit of the electric rail (M1), resulting in a } 10 \text { minute operation } \\
\text { interruption (C3). }\end{array}$ & $\mathrm{E} 1, \mathrm{M} 1, \mathrm{C} 3$ & $\mathrm{E} 1 \rightarrow \mathrm{M} 1 \rightarrow \mathrm{C} 3$ \\
\hline 208 & $\begin{array}{l}\text { On April 18,2009, at Nanjing metro line } 1 \text {, the dispatcher did not release the instruction to } \\
\text { the switch machine as planed (S3). The driver passed through the turnout zone without } \\
\text { confirming whether the switch direction was consistent with the target direction, despite a } \\
\text { red light warning of the switch position indicator (S5). This damaged the turnout (M6) and } \\
\text { led to an operation interruption of dozens of minutes (C3). }\end{array}$ & S3, S5, M6, C3 & $\mathrm{S} 3 \rightarrow \mathrm{S} 5 \rightarrow \mathrm{M} 6 \rightarrow \mathrm{C} 3$ \\
\hline
\end{tabular}

driven by unhealthy physiology or psychology were important factors leading to metro accidents. On the other, passenger behaviors such as falling onto the track (P10) and uncivilized behavior (P3) with great potential to promote accidents deserved special attention. Besides, the dangerous or abnormal state of passenger belongings (P5) was also found to have significant tendency of causing accidents. As for the machine-related factors (NII $=0.0221)$, the failures of track (M6), power supply system (M1), and vehicle (M3) were more likely to trigger metro accidents than other mechanical system failures.

To intuitively display the complex relationships among various factors, an accident network of metro operation was pictured (Figure 3 ). The orange nodes represent the factors involved in high-rank, and the green nodes represent the factors classified into low-rank. The size of the nodes displayed the NII value, and the bigger the nodes are, the higher the values are. Whether there is a relation between every two nodes is determined by the reachability matrix $\mathbf{K}$, which only retains stronger influences that surpass the threshold value $\lambda$. The width of the edges reflects the size of the direct and indirect influences between the factors, obtained from the comprehensive influence matrix T. As shown in Figure 3, the thick directed edges from, e.g., E6 to C5, E1 to M6, and E6 to $\mathrm{C} 2$, suggest that the subsequent factors are strongly influenced by the antecedent factors.

\section{Discussion}

5.1. Validation of the Proposed Method. In order to verify the effectiveness of the proposed method, DC, BC, and CC were utilized to calculate the centrality scores of the nodes in the network (for definitions and formulas of the three classic methods see [56]). Table 6 shows the top- 14 nodes ranked by different methods. It can be seen that our proposed method has 7, 6, 7 same nodes with DC, BC, and CC, respectively. This signifies that the proposed method achieves satisfying performance, which proved the accuracy of the model to a certain extent.

Furthermore, a semi-structured questionnaire survey was conducted with 7 experts (including 3 scholars with pertinent knowledge in the domain of transportation safety and 4 managers of metro operation companies) to evaluate the results of NII ranking. The questionnaire consisted of the top-14 causal factors and the agreement level of the significance of each factor rating on a scale of 1-6. The scale intervals are defined as follows: $1=$ "strongly disagree", 2 = "disagree", 3 = "somewhat disagree", 4 = "somewhat agree", 5= "agree", and 6= "strongly agree". All the experts were invited to fill out the questionnaire based on their knowledge and experience of transportation safety. The results showed that the mean scores for agreement level of each factor were all over 4.5, indicating that the experts 


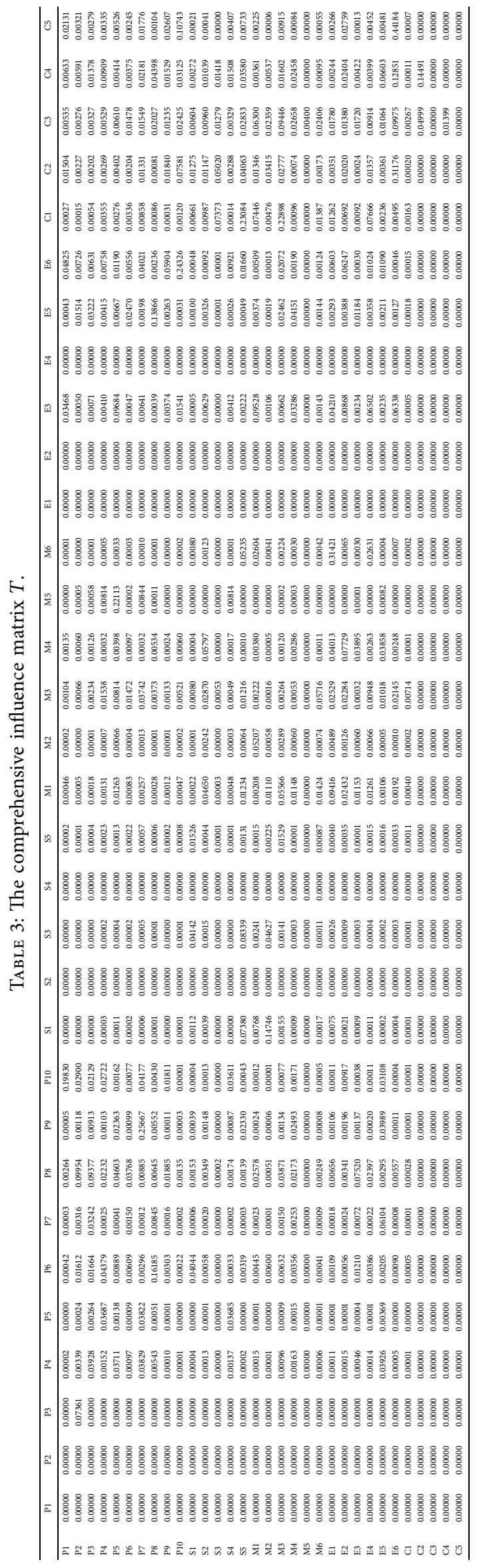


| J10000000000000000000000000-70-0 -0 O3000000000000000-0-00000000-00-00 ปิ $000000000-00-0000000000000-0-000$ U $000000000000-0-t 0-000000-00-0000$ 苜 $00000000-1000000000000-1000-100000$ m $10000000-00000000000000000-000000$ H m $0000-0000000000-0000000-70-00000$ त्ञ⿰0000000000000000000000-1000000000 피 $000000000000000000000-0000000000$ $\sum 00000000000000-00000-10000000000$ $\sum 0000-00000000000000-000000000000$ I $\sum^{m} 00000000000000000-100-00000000000$ I $000000000000000-11000000000000000$ I \& $00000000000000-00000000000000000$ W0000000000000-000000000000000000

\$ $000000000000-0-00000000000000000$ N $00000000000-00000000000000000000$ ज $0000000000-000-0-000000000000000$ $\stackrel{0}{2}-00000000-0000000000000000000000$ $\$ 000000-0-00000000000000000000000$ $\stackrel{\infty}{\infty} 0-70000-000000000000000-00000000$ a $000000-000000000000000000-000000$ $200000-0-000000000000000000000000$ R $0000-000000000000000000000000000$ I $1000-0000000000000000000000000000$ $\approx 0-700000000000000000000000000000$ N $0-000000000000000000000000000000$ $\vec{a}-0000000000000000000000000000000$

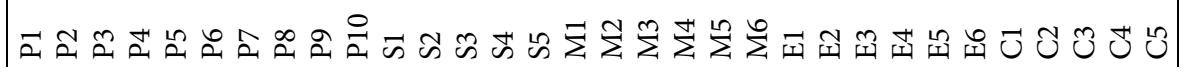




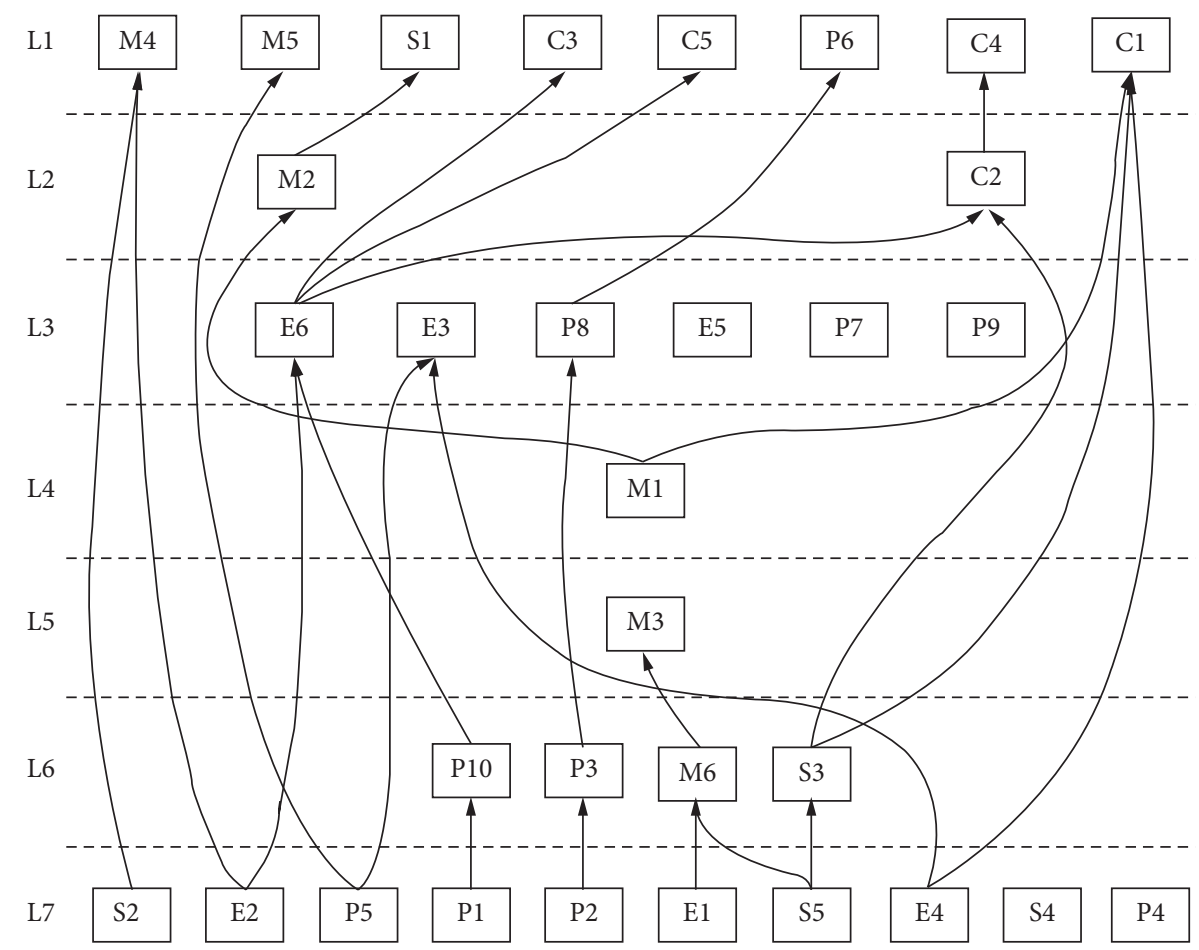

FIGURE 2: The multilevel hierarchical model of causal factors regarding metro-operation accidents.

agreed with the significant contributions of the 14 high-rank factors to metro accidents.

\subsection{Research Implications}

5.2.1. Staff-Related Factors. According to the results of NII, the staff-related factors ranked first of all the factor categories, in which "driver noncompliance (S5)" and "traffic dispatching errors (S3)" acquired the top priority. This indicates that the errors of drivers and dispatchers are normally associated closely with metro accidents compared to other professions, which is supported by a number of prior studies. For example, Zhao et al. [57] suggested that the safety policy of train should present concern for decreasing the system risk through avoidance of driver errors. As indicated by Wang and Fang [52], identifying the error behavior of traffic dispatchers in emergency scenario is beneficial to mitigate the accidents of grave consequence. In fact, since in the case of emergency the automatic train control system is closed or lose a part of safety protection function, the effectiveness of emergency disposal is heavily dependent upon manual operation, coordination, and monitoring of drivers and dispatchers. On account of this, appropriate strategies should be developed to avoid violations or errors from metro drivers and dispatchers.

According to human factor analysis and classification system [58], violations and errors are two typical types of unsafe human acts in view of the emotional and motivational distinctions behind the behaviors. In a railway safety context, violations refer to a willful disregard for the rules and regulations that govern safe train operation [59], while errors most often were the result of unintentional wrong operations because of wrong judgement and wrong response to emergency situations or inappropriate operation process [60]. A scrutiny of accident cases collected in this study suggested that the noncompliance behavior of drivers and dispatchers can be largely attributed to unintentional errors, and more precisely are derived from their attention failures or improper decisions. It is, thus, essential for metro managers to take measures directed to amending the unintentional error behavior of drivers and dispatchers.

5.2.2. Environment-Related Factors. "Extrinsic nature disturbance (E1)" refers to the natural disaster that is unpredictable and disastrous to metro operation, such as earthquake, freezing climate, rainstorm, and snow. The accident network of metro operation indicated that natural disasters are closely related to power supply failure (M1) and reduction of track safety performance (M6), which was also supported by Wang et al. [61] who proposed that extreme weather will lead to power outages and track creep of railways.

"Extrinsic non-nature disturbance (E2)", as the second important environment-related factors, was found to result in multiple damaging consequences of, e.g., "collision (C2)", "degradation of operation service (C3)", "casualties (C4)", and "occupational injuries (C5)", uniformly through "intrusion of the metro gauge (E6)". This to some extent indicates that whether the disturbance factors intrude into the gauge or protection area of the metro plays a decisive role in the generation of substantive accident outcomes. Similar evidence also comes from Wan et al. [46] who confirmed that intrusion into the gauge of metros was the pivotal node of various paths leading to operation accidents with 
TABLE 5: The node importance index.

\begin{tabular}{|c|c|c|}
\hline Accident causal factors & $\begin{array}{c}\text { NII } \\
\text { values }\end{array}$ & $\begin{array}{l}\text { NII } \\
\text { ranking }\end{array}$ \\
\hline \multicolumn{3}{|l|}{ High-rank } \\
\hline S5. Driver noncompliance & 0.1436 & 1 \\
\hline E1. Extrinsic nature disturbance & 0.0837 & 2 \\
\hline P2. Passenger sudden illness & 0.0782 & 3 \\
\hline M6. Track failures & 0.0559 & 4 \\
\hline P1. Passenger suicide & 0.0559 & 5 \\
\hline P10. Passenger falling onto the tracks & 0.0470 & 6 \\
\hline P5. Passenger belonging aberration & 0.0382 & 7 \\
\hline E2. Extrinsic non-nature disturbance & 0.0382 & 8 \\
\hline E4. Design and construction faults & 0.0382 & 9 \\
\hline S3. Traffic dispatching errors & 0.0358 & 10 \\
\hline M1. Power supply failures & 0.0304 & 11 \\
\hline E6. Intrusion of the metro gauge & 0.0303 & 12 \\
\hline P3. Passenger uncivilized behaviors & 0.0298 & 13 \\
\hline M3. Vehicle failures & 0.0262 & 14 \\
\hline \multicolumn{3}{|l|}{ Low-rank } \\
\hline E3. Fire or flood & 0.0226 & 15 \\
\hline P8. Passenger panic & 0.0203 & 16 \\
\hline C1. Derail & 0.0164 & 17 \\
\hline S2. Poor maintenance & 0.0159 & 18 \\
\hline M4. Station facility failures & 0.0106 & 19 \\
\hline C2. Collision & 0.0100 & 20 \\
\hline E5. Congestion & 0.0091 & 21 \\
\hline S1. Information delivery errors & 0.0062 & 22 \\
\hline P7. Passenger dangerous behaviors & 0.0059 & 23 \\
\hline P9. Passenger got stuck & 0.0059 & 24 \\
\hline M5. Platform screen door failures & 0.0053 & 25 \\
\hline $\begin{array}{l}\text { M2. Signal and communication system } \\
\text { failures }\end{array}$ & 0.0042 & 26 \\
\hline C3. Degradation of operation service & 0.0042 & 27 \\
\hline C5. Occupational injuries & 0.0037 & 28 \\
\hline C4. Passenger casualties & 0.0030 & 29 \\
\hline P6. Improper use of facilities & 0.0011 & 30 \\
\hline P4. Personal conflicts & 0.0000 & 31 \\
\hline S4. Inadequate station inspection & 0.0000 & 32 \\
\hline \multicolumn{3}{|c|}{$\begin{array}{l}\text { Mean NII value of each factor category: } \mathrm{S}=0.0403, \mathrm{E}=0.0370 \text {, } \\
\mathrm{P}=0.0282, \mathrm{M}=0.0221, \mathrm{C}=0.0075\end{array}$} \\
\hline
\end{tabular}

Note: S: staff-related factors, E: environment-related factors, P: passengerrelated factors, M: machine-related factors, C: consequence-related factors.

significant effects. As a factor, which is directly associated with many negative consequences, the intrusion of metro gauge should be given great importance in order to effectively forestall metro accidents.

"Design and construction faults (E4)", which are the problems left back from the design or construction stage of metros, normally embodies inappropriate equipment selection and design deficiency of metro facilities, for example, the over wide distance between the train and the platform. Prior studies have suggested that safety and security issues of construction projects need to be considered from a lifecycle perspective, i.e., carrying out "design for safety (DFS)" [62], because design defects with the potential to cause operational malfunctions or accidents are irreparable during the operation stage [63]. However, Xiahou et al. [64] suggested that, despite its potential benefits, DFS has not been sufficiently adopted in the industry of China because of numerous barriers coming from cost, legislation, and procurement methods.
TABLE 6: Top-14 nodes selected by different methods.

\begin{tabular}{lcccc}
\hline Rank & DC & BC & CC & Proposed method \\
\hline 1 & E6 & P8 & M2 & S5 \\
2 & M1 & E3 & C2 & E1 \\
3 & E3 & E5 & S2 & P2 \\
4 & P8 & E6 & S3 & M6 \\
5 & C1 & P7 & E6 & P1 \\
6 & S5 & P9 & P9 & P10 \\
7 & P10 & M1 & P10 & P5 \\
8 & M3 & M3 & E2 & E4 \\
9 & C2 & M6 & P7 & E2 \\
10 & M6 & P10 & P8 & S3 \\
11 & S3 & M2 & M1 & M1 \\
12 & E5 & C2 & E5 & E6 \\
13 & C3 & S3 & P1 & P3 \\
14 & C4 & C1 & P2 & M3 \\
\hline
\end{tabular}

5.2.3. Passenger-Related Factors. The results indicated that "passenger sudden illness (P2)" and "passenger suicide (P1)" driven by their physiology or psychology were of great importance in the passenger-related factors. It was found that P2 is likely to cause "passenger panic (P8)". The reason may be that passengers tend to fall ill suddenly in the circumstances of huge passenger flow, which would throw the passengers who are not clear about the situation into turmoil. On the other hand, by way of falling on the track (P10) and intruding into gauge (E6), passenger suicide (P1) was very likely to be linked to serious consequences such as collision, injuries, and casualties. Thus, there is an urgent need to prevent passengers from suicide as well as their invasion into the dangerous track area.

In addition to passenger behaviors, this study found that the goods carried by passengers, if being potentially dangerous (e.g., items left on the platform), can also pose threat to metro operation safety. This is supported by the finding of Wan et al. [47], who have highlighted the influence of passenger belongings aberration on metro safety by assessing the hazardous level of diverse risky riding behaviors of passengers. In the metro practice of China, metrooperation companies of different cities have published rules of restricted items regarding metro riding, and the majority of passengers could abide by these rules. It is, however, often the case that items not yet covered by the restricted list but with unexpected dangers (e.g., balloon and power bank) have increasing tendency of causing operation malfunction and public panic.

5.2.4. Machine-Related Factors. "Track failures (M6)", "power supply failures (M1)", and "vehicle failures (M3)" were found to be important factors for reducing metro accidents. These findings are reasonable because compared to other systems or facilities (e.g., station facility and platform screen door), power supply, the track, and the vehicle directly underpinning the train operation will most probably trigger the consequences of service degradation (C3), especially delays. This is in line with the findings of Weng et al. [54] who suggested that the failures of power equipment and vehicle have adverse effects on the schedule adherence of 


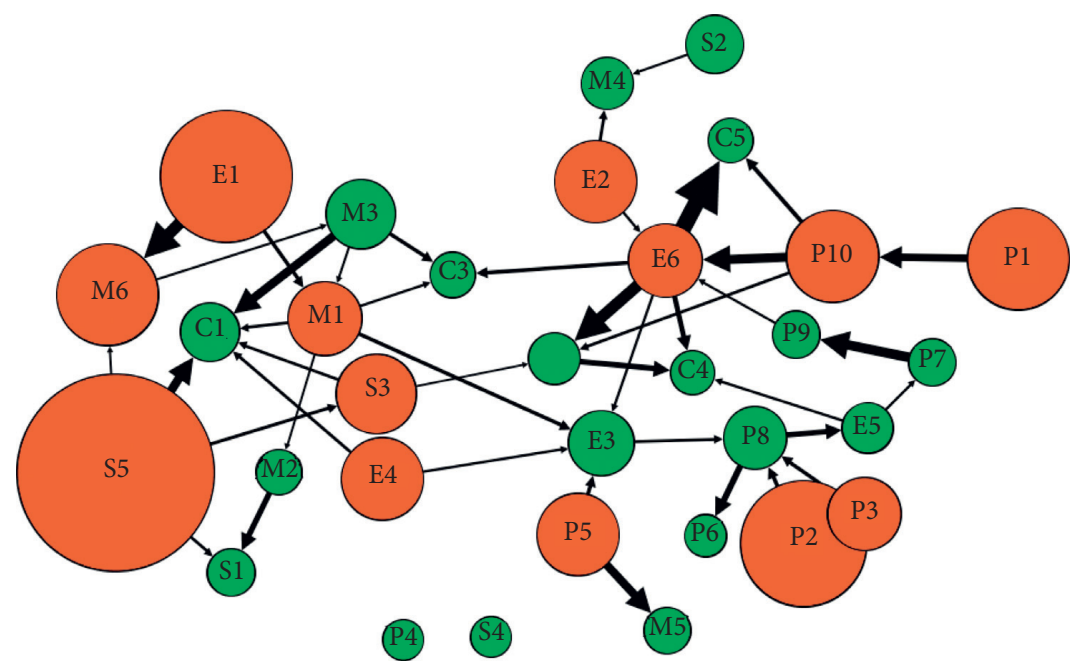

Figure 3: Accident network of metro operation.

train operation and due to the difficulty in detecting and locating power failures, it would like to cause longer delays. M3 was, on the other hand, found to be strongly associated with derail (C1). For instance, a common case is that the loss of emergency braking ability makes the vehicle fail to slow down and finally run off the track. More importantly, our findings suggested that there are significant cascading effects in the failure of the three systems. For example, the degradation of track performance (e.g., slippery in rainy day) (M6) often leads to the malfunction of the vehicle's braking system (M3), and the short circuit of some components on the vehicle (M3) (e.g., pantograph and insulator) may cause the entire failure of the power supply system (M1).

5.2.5. Suggestions for Metro Operation Safety. Based on the implications discussed above, the following suggestions derived from the findings of this study are recommended for daily metro operation management:

(1) Given that drivers' and dispatchers' error behavior mainly result from attention failure and improper decision, behavioral interventions should be conducted in the aspect of improving safety awareness and professional abilities. On the one hand, metro safety culture should be cultivated to form better safety values of metro operation companies and employees. First, it is essential for the metro company to allocate adequate resources, time, and inspections for safety improvement, since it is a demonstration of management commitment, which plays a key role in promoting the safety culture [65]. Second, employee participation in metro safety management should be added in company's management system in a simple and convenient way of involving them in safety regular meetings. On the other hand, considering that unintentional errors of drivers and dispatchers usually involve inappropriate operation or response to emergencies, standardized prejob training, and regular guidance should be strengthened, directed to increasing operational and responsive abilities in emergency scenario.

(2) For the uncontrollable and variable extrinsic disturbances, real-time warning and emergency drill modules should be underscored in emergency plans so as to detect the contingency event timely and as well take an effective response according to the scenarios. Furthermore, the installation of platform screen doors has been proven as an effective way to decrease the likelihood of intruding into the gauge [66]. However, gauge intrusion incidents resulting from passengers or items carried by them occurred unceasingly in China, despite the fact that most metro stations have installed platform screen doors. Therefore, the on-site patrol of the train operation and passenger riding behavior should be strengthened. In addition, policies aiming at regularizing the behavior of metro riders, such as assisting to stand guard, reading regulations, and watching educational videos, should be formulated to guard against trespassing on the metro gauge. To promote DFS in the delivery of the public infrastructure such as metros, incentives, and support policies should be established by the government to encourage owners to adopt DFS and increase designers' involvement in the lifecycle safety management. Moreover, the DFS ability of designers can be enhanced by providing training courses related to DFS and promoting advanced technologies (e.g., virtual reality and BIM) in construction industry.

(3) In metro practice, station attendants who are given basic medical treatment training usually serve concurrently as first-aid personnel in case of an emergency. To reduce the risk of passenger suicide and illness, metro operation companies should employ full-time medical staff with corresponding qualifications, instead of setting a part-time position for medical help, to provide a more professional first-aid 
treatment and better avoid passenger panic when injuries or sudden diseases occur. Besides, monitoring of the items carried by passengers should be strengthened and should be kept advance with time. With the development of socioeconomy, new products emerge continuously, which not only enrich people's material life and meet the needs of diversified life, but also bring potential safety hazards to metro operation. This requires the metro mangers to regularly amend the list of prohibited dangerous items according to the risk assessment based on realtime monitor data and disseminate the updated list to the public through modern ways, such as social platforms.

(4) As the track, power supply, and vehicle system play a more important role in causing metro accidents than other mechanical systems, top priority should be given to these systems regarding safety resource allocation and preventative strategy development. Considering the cascade effects between track, vehicle, and power systems, it is necessary to strengthen the communication and mutual learning of professional knowledge among rail and vehicle workers and electricians. On the one hand, a regular symposium program should be established to carry out multidisciplinary diagnosis and analyses of normal or abnormal accident cases and summarize the conduction and cascade relationship of the faults in the cases. On the other hand, workers' ability to cope up with complex and synthetical problems should be checked and evaluated to promote multiple professional coordination between different types of workers.

\section{Conclusion}

This study comprehensively explored the interrelationships between humans, machines, and environment in metrooperation accidents and identified important accident causes by using a novel hybrid method of node importance evaluation. Taking advantage of DEMATEL and ISM, the proposed method determined the node ranking by considering not only the nature of the accident network topology, but also the discrepant contributions of the node to accident development. Drawing on the relations of different factors obtained from real accident cases, the node importance index of each node in the accident network of metro operation was calculated to prioritize 32 accident casual factors, and the results were compared with other traditional methods to verify the effectiveness of the proposed method. Then, focusing on 14 casual factors with higher NII, implications, and suggestions for improving metro operation safety were highlighted and discussed. The calculation results confirmed the effectiveness and appropriateness of the proposed method on ranking the nodes in accident networks. The main conclusions are illustrated below.

First, behavioral intervention measures should directly boost the safety awareness and professional abilities of metro drivers and dispatchers whose errors were found to be derived from attention failure and improper decision. Second, real-time warning and emergency drill should be reinforced to cope up with the unpredictable extrinsic disturbances. The on-site supervision and regulation of passengers' behavior are essential for avoiding intrusion of the metro gauge. In order to refrain from the safety problems due to design and construction faults, support policies of DFS should be formulated and applied for metro industry. Third, passenger illness and suicide, as well as the items carried by passengers, were found to be the factors closely related to metro accidents, which would be mitigated by adding specialized medical personnel and, for the latter, by timely updating the list of prohibited dangerous items. Finally, top priority should be given to track, vehicle, and power supply system, with regard to the resource allocation of safety management, and multiple professional coordination should be encouraged to respond to the cascading effects of system failures.

Some limitations in this study are noted. Since the proposed method is case-based, the quality of the cases upon which the accident analysis is conducted largely determines the effectiveness of the analysis. Lack of formal records or authoritative approaches to obtain historical cases might limit the accuracy and generalization of the method. In this situation, despite being somewhat subjective compared to the case-based analysis, expert rights should be given priority in the analysis, as the relations between factors can be determined artificially by the DEMATEL and ISM methods. In the future, the rule-based reasoning method, which solves new problems by retrieving existing successful solutions of similar problems from the general knowledge of the domain, can be integrated to improve the applicability of the proposed method. Furthermore, there might be discrepant characteristics of metro accidents in different countries due to their different social cultures, management systems, and development stage. Given that the accident cases used in this study were mainly collected from China, caution should be taken with attempt to generalize our findings to other countries or regions.

\section{Data Availability}

The data used to support the findings of this study are available from the corresponding author upon request.

\section{Conflicts of Interest}

The authors declare that they have no conflicts of interest.

\section{Acknowledgments}

This study was supported by the Youth Project of the National Natural Science Foundation of China (grant number 71802071), the Youth Project of Humanities and Social Science Fund of Ministry of Education of China (grant number 18YJCZH166), and the Fundamental Research Funds for the Central Universities (grant number B200202044). 


\section{References}

[1] Union Internationale des Transports Publics (UITP), World Metro Figures 2018, 2018, https://cms.uitp.org/wp/wp-content/ uploads/2020/06/Statistics-Brief-World-metro-figures-2018V3_ WEB.pdf.

[2] R. R. M. Gershon, K. A. Qureshi, M. A. Barrera, M. J. Erwin, and F. Goldsmith, "Health and safety hazards associated with subways: a review," Journal of Urban Health: Bulletin of the New York Academy of Medicine, vol. 82, no. 1, pp. 10-20, 2005.

[3] X. Ren and L. L, "Review of ranking nodes in complex networks (in Chinese)," Chinese Science Bulletin, vol. 59, no. 13, pp. 1175-1197, 2014.

[4] Q. Li, L. Song, G. F. List, Y. Deng, Z. Zhou, and P. Liu, "A new approach to understand metro operation safety by exploring metro operation hazard network (MOHN)," Safety Science, vol. 93, pp. 50-61, 2017.

[5] X. Wen, C. Tu, and M. Wu, "Node importance evaluation in aviation network based on "no return" node deletion method," Physica A: Statistical Mechanics and its Applications, vol. 503, pp. 546-559, 2018.

[6] D. H. Kim, D. A. Eisenberg, Y. H. Chun, and J. Park, "Network topology and resilience analysis of South Korean power grid," Physica A: Statistical Mechanics and its Applications, vol. 465, pp. 13-24, 2017.

[7] N. Hafiene, W. Karoui, and L. Ben Romdhane, "Influential nodes detection in dynamic social networks: a survey," Expert Systems with Applications, vol. 159, Article ID 113642, 2020.

[8] Y. Yang and G. Xie, "Efficient identification of node importance in social networks," Information Processing \& Management, vol. 52, no. 5, pp. 911-922, 2016.

[9] W. Li, L. Zhang, and W. Liang, "An accident causation analysis and taxonomy (ACAT) model of complex industrial system from both system safety and control theory perspectives," Safety Science, vol. 92, pp. 94-103, $2017 \mathrm{~b}$.

[10] Z. H. Qureshi, "A review of accident modelling approaches for complex critical sociotechnical systems," Define Science Technology Organs, vol. 86, pp. 47-59, 2008.

[11] H. W. Heinrich, Industrial Accident Prevention: A Scientific Approach, McGraw-Hill, New York, NY, USA, 1931.

[12] L. Benner, "Accident investigations: multilinear events sequencing methods," Journal of Safety Residence, vol. 7, 1975.

[13] P. Katsakiori, G. Sakellaropoulos, and E. Manatakis, "Towards an evaluation of accident investigation methods in terms of their alignment with accident causation models," Safety Science, vol. 47, no. 7, pp. 1007-1015, 2009.

[14] E. Matsika, S. Ricci, P. Mortimer, N. Georgiev, and C. O’Neill, "Rail vehicles, environment, safety and security," Research in Transportation Economics, vol. 41, no. 1, pp. 43-58, 2013.

[15] M. Kumar and M. Kaushik, "System failure probability evaluation using fault tree analysis and expert opinions in intuitionistic fuzzy environment," Journal of Loss Prevention in the Process Industries, vol. 67, Article ID 104236, 2020.

[16] H. Hajian-Hoseinabadi, M. E. H. Golshan, and H. A. Shayanfar, "Composite automated distribution system reliability model considering various automated substations," International Journal of Electrical Power \& Energy Systems, vol. 54, pp. 211-220, 2014.

[17] D. M. Shalev and J. Tiran, "Condition-based fault tree analysis (CBFTA): a new method for improved fault tree analysis (FTA), reliability and safety calculations," Reliability Engineering \& System Safety, vol. 92, no. 9, pp. 1231-1241, 2007.

[18] M. Li, H. Wang, D. Wang, Z. Shao, and S. He, "Risk assessment of gas explosion in coal mines based on fuzzy AHP and bayesian network," Process Safety and Environmental Protection, vol. 135, pp. 207-218, 2020.

[19] F. Li, W. Wang, S. Dubljevic, F. Khan, J. Xu, and J. Yi, "Analysis on accident-causing factors of urban buried gas pipeline network by combining DEMATEL, ISM and BN methods," Journal of Loss Prevention in the Process Industries, vol. 61, pp. 49-57, 2019.

[20] M. Yao, Y. Fang, W. Tang, and J. Zhou, "Study on safety behavior planning theory and control strategies for coal chemical workers," Safety Science, vol. 128, Article ID 104726, 2020.

[21] J. Liu, F. Schmid, W. Zheng, and J. Zhu, "Understanding railway operational accidents using network theory," Reliability Engineering \& System Safety, vol. 189, pp. 218-231, 2019.

[22] S. Guo, X. Zhou, B. Tang, and P. Gong, "Exploring the behavioral risk chains of accidents using complex network theory in the construction industry," Physica A: Statistical Mechanics and its Applications, vol. 560, Article ID 125012, 2020.

[23] Z. Zhou, J. Irizarry, and Q. Li, "Using network theory to explore the complexity of subway construction accident network (SCAN) for promoting safety management," Safety Science, vol. 64, pp. 127-136, 2014.

[24] H. Chen, L. Zhang, and L. Ran, "Vulnerability modeling and assessment in urban transit systems considering disaster chains: a weighted complex network approach," International Journal of Disaster Risk Reduction, vol. 54, Article ID 102033, 2021.

[25] J. Liu, Q. Xiong, W. Shi, X. Shi, and K. Wang, "Evaluating the importance of nodes in complex networks," Physica A: Statistical Mechanics and its Applications, vol. 452, pp. 209-219, 2016.

[26] M. Lu, "Node importance evaluation based on neighborhood structure hole and improved TOPSIS," Computer Networks, vol. 178, Article ID 107336, 2020.

[27] H. Liao, M. S. Mariani, M. Medo, Y. C. Zhang, and M. Y. Zhou, "Ranking in evolving complex networks," Physics Reports, vol. 689, pp. 1-54, 2017.

[28] J. Liu, X. Li, and J. Dong, "A survey on network node ranking algorithms: representative methods, extensions, and applications," Science China Technological Sciences, vol. 64, no. 3, pp. 451-461, 2021a.

[29] L. C. Freeman, "Centrality in social networks conceptual clarification,” Social Networks.vol. 1, no. 3, pp. 215-239, 1979.

[30] D. Chen, L. Lü, M. S. Shang, and Y. C. Zhang, "Identifying influential nodes in complex networks," Physica A, vol. 391, pp. 1777-1787, 2012.

[31] P. Bonacich, "Power and centrality: a family of measures," American Journal of Sociology, vol. 92, no. 5, pp. 1170-1182, 1987.

[32] S. Brin and L. Page, "The anatomy of a large-scale hypertextual web search engine," Computer Network ISDN System, vol. 30, no. 1, pp. 107-117, 1998.

[33] L. Lü, D. Chen, X. Ren, Q. Zhang, Y. Zhang, and T. Zhou, "Vital nodes identification in complex networks," Physics Reports, vol. 650, pp. 1-63, 2016.

[34] L. Wang, S. Zheng, Y. Wang, and L. Wang, "Identification of critical nodes in multimodal transportation network," Physica A, vol. 580, Article ID 126170, 2021.

[35] H. Liu, S. Luo, J. Gan, and Y. Wu, "Research on node importance of power communication network based on multiattribute analysis," in Proceedings of the IEEE 4th Information 
Technology, Networking, Electronic and Automation Control Conference, pp. 2683-2687, Nanning, China, June 2020.

[36] P. Liu, L. Li, S. Fang, and K. Yao, "Identifying influential nodes in social networks: a voting approach," Chaos Solitons Fractals, vol. 152, Article ID 111309, 2021b.

[37] H. Mo and Y. Deng, "Identifying node importance based on evidence theory in complex networks," Physica A, vol. 529, Article ID 121538, 2019.

[38] Z. Liu, C. Jiang, J. Wang, and H. Yu, "Knowledge-based systems the node importance in actual complex networks based on a multi-attribute ranking method," KnowledgeBased System, vol. 84, pp. 56-66, 2015.

[39] Y. Meng, X. Tian, Z. Li, W. Zhou, and Z. Zhou, "Exploring node importance evolution of weighted complex networks in urban rail transit," Physica A, vol. 558, Article ID 124925, 2020.

[40] G. Hu, X. Xu, and X. Guo, "Importance calculation of complex network nodes based on interpretive structural modeling method (in China)," Journal of Zhejiang University Science A, vol. 52, pp. 1989-2022, 2018.

[41] R. S. Burt, Structural Holes: The Social Structure of Competition, Harvard University Press, Boston, MA, USA, 1992.

[42] R. C. Goduscheit, D. Khanin, R. V. Mahto, and W. C. McDowell, "Structural holes and social entrepreneurs as altruistic brokers," Journal of Innovation and Knowledge, vol. 6, no. 2, pp. 103-111, 2021.

[43] S. Dindar, S. Kaewunruen, M. An, and J. M. Sussman, "Bayesian network-based probability analysis of train derailments caused by various extreme weather patterns on railway turnouts," Safety Science, vol. 110, pp. 20-30, 2018.

[44] W. Huang, Y. Liu, Y. Zhang et al., "Fault tree and fuzzy D-S evidential reasoning combined approach: an application in railway dangerous goods transportation system accident analysis," Information Science, vol. 520, pp. 117-129, 2020.

[45] B. L. Mishara and C. Bardon, "Characteristics of railway suicides in Canada and comparison with accidental railway fatalities: implications for prevention," Safety Science, vol. 91, pp. 251-259, 2017.

[46] X. Wan, Q. Li, and J. Yuan, "Identifying critical path to metro operation delay incident due to passengers' aberrant behavior (in China)," China Safety Science Journal, vol. 24, pp. 152-158, 2014.

[47] X. Wan, Q. Li, J. Yuan, and P. M. Schonfeld, "Metro passenger behaviors and their relations to metro incident involvement," Accident Analysis and Prevention, vol. 82, pp. 90-100, 2015.

[48] M. Kyriakidis, R. Hirsch, and A. Majumdar, "Metro railway safety: an analysis of accident precursors," Safety Science, vol. 50, pp. 1535-1548, 2012.

[49] H. J. Kim, J. J. Jeong, J. Wook Kim, and J. K. Oh, “A factor analysis of urban railway casualty accidents and establishment of preventive response systems," Procedia-Social and Behavioral Science, vol. 218, pp. 131-140, 2016.

[50] M. T. Baysari, A. S. Mcintosh, and J. R. Wilson, "Understanding the human factors contribution to railway accidents and incidents in Australia," Accident Analysis and Prevention Journal, vol. 40, pp. 1750-1757, 2008.

[51] L. Chang, W. Dong, J. Yang, X. Sun, and X. Xu, "Hybrid belief rule base for regional railway safety assessment with data and knowledge under uncertainty," Information Science, vol. 518, pp. 376-395, 2020.

[52] J. Wang and W. Fang, "A structured method for the traffic dispatcher error behavior analysis in metro accident investigation," Safety Science, vol. 70, pp. 339-347, 2014.
[53] M. T. Baysari, C. Caponecchia, A. S. Mcintosh, and J. R. Wilson, "Classification of errors contributing to rail incidents and accidents: a comparison of two human error identification techniques," Safety Science, vol. 47, pp. 948-957, 2009.

[54] J. Weng, Y. Zheng, X. Yan, and Q. Meng, "Development of a subway operation incident delay model using accelerated failure time approaches," Accident Analysis Prevention, vol. 73, pp. 12-19, 2014.

[55] X. Zhang, Y. Deng, Q. Li, M. Skitmore, and Z. Zhou, “An incident database for improving metro safety: the case of shanghai," Safety Science, vol. 84, pp. 88-96, 2016.

[56] T. Opsahl, F. Agneessens, and J. Skvoretz, "Node centrality in weighted networks: generalizing degree and shortest paths," Social Networks, vol. 32, no. 3, pp. 245-251, 2010.

[57] B. Zhao, T. Tang, and B. Ning, "System dynamics approach for modelling the variation of organizational factors for risk control in automatic metro," Safety Science, vol. 94, pp. 128-142, 2017.

[58] S. A. Shappell and D. A. Wiegmann, "A human error approach to accident investigation: the taxonomy of unsafe operations," International Journal of Aviation Psychology, vol. 7, pp. 269-291, 1997.

[59] J. Zhou and Y. Lei, "Paths between latent and active errors: analysis of 407 railway accidents/incidents' causes in China," Safety Science, vol. 110, pp. 47-58, 2018.

[60] Q. Zhan, W. Zheng, and B. Zhao, "A hybrid human and organizational analysis method for railway accidents based on HFACS-railway accidents (HFACS-RAs)," Safety Science, vol. 91, pp. 232-250, 2017.

[61] G. Wang, T. Xu, T. Tang, T. Yuan, and H. Wang, "A bayesian network model for prediction of weather-related failures in railway turnout systems," Expert Systems Applications, vol. 69, pp. 247-256, 2017.

[62] R. Szymberski, "Construction project safety planning," Tappi Journal, vol. 80, pp. 69-74, 1997.

[63] J. Yuan, X. Li, X. Xiahou, N. Tymvios, Z. Zhou, and Q. Li, "Accident prevention through design $(\mathrm{PtD})$ : integration of building information modeling and PtD knowledge base," Automation in Construction, vol. 102, pp. 86-104, 2019.

[64] X. Xiahou, J. Yuan, Q. Li, and M. J. Skibniewski, "Validating DFS concept in lifecycle subway projects in China based on incident case analysis and network analysis," Journal of Civil Engineering Management, vol. 24, pp. 53-66, 2018.

[65] R. Choudhry, D. Fang, and S. Mohamed, "The nature of safety culture: a survey of the state-of-the-art," Safety Science, vol. 45, pp. 993-1012, 2007.

[66] Y. Xing, J. Lu, and S. Chen, "Evaluating the effectiveness of platform screen doors for preventing metro suicides in China," Journal of Affective Disorder, vol. 253, pp. 63-68, 2019. 